\title{
Dynamic Alteration in Cerebral Total Hemoglobin Concentration Measured Using Portable Near-infrared Spectroscopy in Orthostatic Hypotension and Intolerance
}

\section{Jae-Myoung Kim}

School of Electrical Engineering, Korea Advanced Institute of Science and Technology (KAIST), Daejeon

\section{Kyung-II Park}

Department of Neurology, Seoul National University College of Medicine, Seoul National University Hospital Healthcare System Gangnam Center, Seoul

\section{Su-Yeon Choi ( $\nabla$ sychoi9@gmail.com )}

Division of Cardiology, Department of Internal Medicine, Seoul National University College of Medicine, Seoul National University Hospital Healthcare System Gangnam Center, Seoul

\section{Hyo Eun Park}

Division of Cardiology, Department of Internal Medicine, Seoul National University College of Medicine, Seoul National University Hospital Healthcare System Gangnam Center, Seoul

\section{Heesun Lee}

Division of Cardiology, Department of Internal Medicine, Seoul National University College of Medicine, Seoul National University Hospital Healthcare System Gangnam Center, Seoul

Hyeon-Min Bae

School of Electrical Engineering, Korea Advanced Institute of Science and Technology (KAIST), Daejeon

\section{Research Article}

Keywords: cerebral hemodynamics, orthostatic hypotension, orthostatic intolerance, near infrared spectroscopy

Posted Date: January 3rd, 2022

DOI: https://doi.org/10.21203/rs.3.rs-1183591/v1

License: (c) (i) This work is licensed under a Creative Commons Attribution 4.0 International License. Read Full License 


\section{Abstract}

A portable near infrared spectroscopy (NIRS) system was used to evaluate alterations in cerebral total hemoglobin concentration $(\mathrm{HbT})$ in individuals with orthostatic hypotension $(\mathrm{OH})$ and orthostatic intolerance $(\mathrm{OI})$ symptoms. We enrolled 238 healthy participants (mean age, 47.9 years) and assessed the presence of $\mathrm{OH}$ (orthostatic blood pressure (BP) drop of systolic BP $\geq 20 \mathrm{mmHg}$ or diastolic $\mathrm{BP} \geq 10 \mathrm{mmHg}$ within 3 minutes of supine-to-stand) and Ol symptoms using the $\mathrm{OH}$ questionnaire. The participants were categorized into three groups based on the presence of $\mathrm{OH}$ and $\mathrm{Ol}$ symptoms: the classic $\mathrm{OH}(\mathrm{OH}-\mathrm{BP})$ group, symptom alone $(\mathrm{OH}-\mathrm{Sx})$ group, and control group. Random casecontrol matching sets (age, sex, hypertension, and diabetes mellitus) were constructed consisting of $16 \mathrm{OH}-\mathrm{BP}$ and 69 $\mathrm{OH}-\mathrm{Sx}$-control sets. We measured the time-derivative of $\mathrm{HbT}$ change in the prefrontal cortex during the squat-to-stand maneuver. There were no differences in demographics, baseline BP, and heart rate among the matched sets. Among the NIRS parameters, the peak-time of maximum slope variation was significantly longer in the $\mathrm{OH}-\mathrm{Sx}$ and $\mathrm{OH}-\mathrm{BP}$ groups than in the matched control groups during transition to the standing position after squatting. Our results suggested that $\mathrm{OH}$ and $\mathrm{Ol}$ symptoms are associated with dynamic alteration in cerebral HbT.

\section{Introduction}

Orthostatic hypotension $(\mathrm{OH})$ is caused by autonomic nervous dysfunction, which compromises cerebral blood flow $(\mathrm{CBF})$ regulation resulting in syncope in severe cases and impairing quality of life ${ }^{[1]}$. It may cause cerebral hypoperfusion and injury and be associated with greater dementia risk in older adults ${ }^{[2,3]}$. Therefore, recent studies have emphasized the importance of investigating $\mathrm{OH}$ and self-reported dizziness. Orthostatic hypotension is diagnosed when there is an orthostatic blood pressure (BP) drop of at least $20 \mathrm{mmHg}$ systolic and/or $10 \mathrm{mmHg}$ diastolic within 3 minutes during the supine-to stand or tilt-table test ${ }^{[4]}$. Conventional methods for diagnosing $\mathrm{OH}$ may require complex equipment, e.g., a tilt-table or continuous BP monitor. Moreover, they have low sensitivity and poor reproducibility despite their high specificity in diagnosing $\mathrm{OH}^{[5]}$. Additionally, provocative drugs, e.g., nitroglycerin or isoproterenol, may lead to adverse effects ${ }^{[6]}$.

Although, measuring peripheral BP variation could be common practice for the diagnosis of $\mathrm{OH}$, monitoring the cerebral hemodynamic response provides signal patterns indicative of regulatory failure of cerebral perfusion upon $\mathrm{OH}$ occurrence ${ }^{[7]}$.

Near-infrared spectroscopy (NIRS) allows noninvasive, continuous, real-time assessment of changes in oxyhemoglobin and deoxyhemoglobin concentrations in the cerebral cortex by detecting the intensity of reflected near infrared light emitted into the brain ${ }^{[8]}$. The recorded brain NIRS signals have been used as indicators of cerebral hemodynamics and autoregulation ${ }^{[9-14]}$.

In this study, we applied portable NIRS to assess changes in cerebral hemodynamics by extracting indicator NIRS parameters from patients with $\mathrm{OH}$ and orthostatic intolerance $(\mathrm{OI})$ symptoms, exploring the association between the observed changes in cardiovascular response and those in cerebrovascular regulation during an orthostatic challenge.

\section{Methods}

\section{Study Population}


We prospectively collected the data of 266 individuals without medical history of (i) cardiovascular diseases, such as heart failure, myocardial infarction, or surgery; (ii) neurodegenerative diseases (e.g., Parkinson's diseases or other types of parkinsonism), or (iii) cerebrovascular disease (e.g., stroke) who visited the Healthcare Center and Neurology or Cardiology Outpatient Clinics at the Healthcare System Gangnam Center, Seoul National University Hospital, and Neurology Department at Seoul National University Hospital between June 2017 and December 2018 (Figure 1). We recruited participants who complained of Ol symptoms (e.g., dizziness, lightheadedness, weakness, fatigue, and feeling faint during the supine-to-stand or sit-to-stand or daily activity interference during standing or walking for a long time in daily life) and volunteers without OI symptoms. The participants were categorized into three groups: the classic $\mathrm{OH}(\mathrm{OH}-\mathrm{BP})$ group, symptom alone (OH-Sx) group, and control group (Figure 1). Participants with a sustained orthostatic BP drop ( $\geq 20 \mathrm{mmHg}$ in systolic BP (SBP) or $\geq 10 \mathrm{mmHg}$ in diastolic BP (DBP) within 3 minutes) during the supine-to-stand test were classified as the $\mathrm{OH}-\mathrm{BP}$ group ${ }^{[4]}$. Participants with no orthostatic BP drop but with an average of the $\mathrm{OH}$ Symptom Assessment (OHSA) score > 2 or an average of OH Daily Activity Scale (OHDAS) score > 2 were classified as the OH-Sx group (see Supplementary Table S1) ${ }^{[15]}$. Finally, participants with no orthostatic BP drop and an average of the OHSA score and OHDAS scores $\leq 2$ were included in the control group. In order to ensure maximal comparability in terms of potential confounders, random case-control matching sets were constructed with respect to the following variables: age (each decade), sex, hypertension (HTN), and diabetes mellitus (DM), which resulted in 1:1 matched case-control sets. Subsequently, the $\mathrm{OH}-\mathrm{BP}$ group was subcategorized into with or without $\mathrm{OH}$ symptoms groups (OH-BP w/ Sx or OH-BP w/o Sx, respectively) using the same criteria applied to categorize the $\mathrm{OH}$ Sx group.

\section{Measurement Protocol}

We first collected baseline BP and heart rate (HR) in a sitting position by averaging two consecutive measurements. To diagnose classical OH, BP and HR were evaluated during the supine-to-stand maneuver (5 minutes in the supine position and 10 minutes of standing)(Figure $2 \mathrm{~A}$ ). The measurements were obtained within a 5 -minute rest in the supine position and then rechecked at 30 seconds and 1, 3, 5, 7, and 9 minutes after standing to evaluate the changes in SBP, DBP, and HR from the supine position during 3 and 10 minutes after standing.

The NIRS system was prepared after longer than 10 minutes of supine-to-stand maneuver, while the participants were sitting in a chair to fully restore their baseline to minimize the contamination of the cardiovascular response. As shown in Figure 2B, a series of total hemoglobin concentration changes was monitored using a portable NIRS system during the squat-to-stand maneuver (1 minute of standing, 2 minutes of squatting, and 10 minutes of standing), similar to a previously reported protocol ${ }^{[9]}$. During NIRS monitoring, BP and HR were also measured at several time points (i.e., within 2-minute rest in the squat position, and at 30 seconds and 1, 3, 5, 7, and 9 minutes after standing). The maximum SBP, DBP fall, and HR increase from the squat position were evaluated during 3 and 10 minutes after standing. All protocols were performed after thorough guidance and practice of performing the maneuvers to minimize motion artifacts caused by posture changes.

Blood pressure and HR were manually measured at each time point using a clinically approved oscillometric device (HEM-780, Omron Corp., Kyoto, Japan) with a cuff placed around the arm over the left brachial artery.

\section{Functional Near-infrared Spectroscopy Data Acquisition and Processing}

A portable NIRS device (NIRSIT; OBELAB Inc., Seoul, Korea, Rep. of) was used to measure changes in cerebral hemodynamics during the squat-to-stand maneuver. Unlike the supine-to-stand maneuver, participants were able to maintain their head upright during the transition of the squat-to-stand maneuver to eliminate motion artifacts from 
cerebral blood volume (CBV) change ${ }^{[16]}$. The NIRS system using a two-wavelength near-infrared laser source (780 $\mathrm{nm}$ and $850 \mathrm{~nm}$ ) of 68 channels in the prefrontal cortex, comprising 24 sources and 32 detectors with a 3-cm sourcedetector distance, were monitored to trace the concentration changes in oxyhemoglobin, deoxyhemoglobin, and total hemoglobin ( $\mathrm{HbT}$, the sum of oxyhemoglobin and deoxyhemoglobin) in the cerebral cortex ${ }^{[17]}$.

The device was placed on the participant's forehead, by aligning the center of the lowermost probes on the FPz as defined by the international 10-20 electroencephalography system (Figure $2 \mathrm{C}$ ). The measurements were recorded at a sampling frequency of $8.13 \mathrm{~Hz}$ and stored in a tablet for data acquisition. Considering the size variation of the forehead according to the different age groups, the channels showing good signal integrity in the middle of the forehead region were bilaterally selected for further analysis (i.e., R: $8,13,21,25,51,54,55$, and 59; L: 24, 28, 36, 41, $58,62,63$, and 66 ). The result of $\mathrm{HbT}$ was filtered using a bandpass filter with a passband frequency ranging from $0.005 \mathrm{~Hz}$ to $0.2 \mathrm{~Hz}$ followed by a 40-tap moving average filter to eliminate high frequency noise and low-frequency drift. The filtered channels were then grouped into left and right sections, and the group signals were averaged. Finally, the $\mathrm{HbT}$ changes in the grouped left and right sections were time differentiated to achieve slope variation of $\mathrm{HbT}$, and then an 8-tap moving average filter was used to remove noise due to differentiation. Accordingly, introduced in our previous study, the minimum and maximum slope variations and corresponding peak times for each hemisphere were calculated from the time-derivative of $\mathrm{HbT}$ change as an objective parameter to assess the recovery rate and speed of CBV arising from the cerebral microvasculature during the posture change ${ }^{[9]}$. Additionally, the average values of the minimum and maximum slope variations and corresponding peak times from the left and right cerebral hemispheres were evaluated for comparisons among the groups.

\section{Statistical Analysis}

Continuous variables were compared using Student's $t$ - or Mann-Whitney U-tests, and the proportions of categorical variables were compared using Pearson's chi-squared $\left(c^{2}\right)$ or Fisher's exact tests $(\mathrm{OH}-\mathrm{Sx}$ or OH-BP vs each matched control). Subcategorization comparisons of the OH-BP group (OH-BP w/ Sx vs OH-BP w/o Sx vs OH-BP matched control) were performed with Kruskal-Wallis test or analysis of variance and post-hoc Bonferroni test, as appropriate. Data are presented as mean \pm standard deviation, and variables were considered statistically significant at $p<0.05$. The case-control matching process was performed using SAS version 9.4 (SAS Institute Inc, Cary, NC). Other statistical analyses were performed using SPSS (version 25.0; IBM Statistics, Armonk, NY, USA) and GraphPad Prism (Version 8, GraphPad Software, San Diego, CA, USA).

\section{Standard Protocol Approvals, Registrations, and Patient Consents}

The study protocol conformed to the guidelines of the Declaration of Helsinki and was approved by the Institutional Review Board of Seoul National University Hospital (IRB No. H-1706-056-859). Informed consent was obtained from all participants.

\section{Results}

\section{Clinical Features and Baseline Demographics}

Twenty-eight participants were excluded from the analysis because of insufficient signal integrity of the NIRS signal. Among the remaining 238 participants, there were 141, 76, and 21 participants in the control, OH-Sx, and OH-BP groups, respectively (Figure 1). After matching the participants according to age, sex, HTN, and DM, the remaining 1:1 matched case-control sets were $69 \mathrm{OH}-\mathrm{Sx}$-control sets and $16 \mathrm{OH}$-BP-control sets. Of the matched OH-BP participants, the $\mathrm{OH}-\mathrm{BP}$ w/ Sx and OH-BP w/o Sx groups included eight participants each. Table 1 summarizes the clinical 
characteristics. There was no difference in age, sex, HTN, DM, and BMI between the OH-BP and OH-Sx groups and each matched control. The questionnaire scores regarding $\mathrm{OH}$ symptom assessment differed significantly among the groups. The OHSA score was higher in the OH-Sx, OH-BP, and OH-BP w/ Sx groups than in the matched-control $(p<$ 0.001). Moreover, the OH-Sx and OH-BP groups had higher OHDAS scores than the control group $(p<0.001$ and $p=$ $0.011, \mathrm{OH}-\mathrm{Sx}$ and $\mathrm{OH}-\mathrm{BP}$, respectively). The participants in the OH-BP w/ Sx group had a higher OHDAS score compared to those in both the control and OH-BP w/o Sx groups $(p<0.001)$. For baseline SBP, DBP, and HR, no significant differences were observed between the $\mathrm{OH}-\mathrm{BP}$ and $\mathrm{OH}-\mathrm{Sx}$ groups and each matched control. The score distribution of OHSA and OHDAS symptoms in each group is illustrated in Supplementary Fig. S1.

\section{Orthostatic Blood Pressure and Heart Rate Alteration According to the Maneuvers}

During the supine-to-stand maneuver, there were no significant differences in maximum SBP, DBP fall, and HR increase during 3 and 10 minutes of standing between the $\mathrm{OH}-\mathrm{Sx}$ and control groups. However, the maximum orthostatic SBP and DBP drops were significantly greater in the $\mathrm{OH}-\mathrm{BP}$ group during the 3 and 10 minutes of standing compared to the control group who experienced slight SBP decrease and DBP increase during the posture change (Table 2). The $\mathrm{OH}-\mathrm{BP}$ group both with and without $\mathrm{OH}$ symptoms had a significant maximum orthostatic SBP drop during both 3 and 10 minutes compared to the matched controls. The OH-BP w/o Sx tended to have a larger DBP drop caused by posture change compared to both the OH-BP w/ Sx and control groups within the first 3 and 10 minutes after standing. The HR increased in all groups during supine-to-stand; however, the difference was statistically insignificant compared to that in the matched controls.

During the squat-to-stand maneuver, 3 and 10 minutes of standing after squatting, the maximum SBP fall showed significant difference in both the $\mathrm{OH}-\mathrm{BP}$ and $\mathrm{OH}-\mathrm{Sx}$ groups than in the control group. The maximum SBP fall was higher in the OH-BP group compared to the matched controls, but $\mathrm{OH}-\mathrm{Sx}$ showed a smaller fall in maximum SBP compared to the matched controls. Moreover, the maximum DBP fall was greater in the OH-BP group compared to the matched control, but the difference did not reach significance (during 3 and 10 minutes, both $p=0.05$ ). In the $\mathrm{OH}-\mathrm{BP}$ subgrouping, the difference in maximum DBP drop for 3 and 10 minutes was significant in the OH-BP w/o Sx group compared to that in the control group. The maximum HR increase after squatting was significantly higher only in the $\mathrm{OH}-\mathrm{Sx}$ group.

\section{Parameters of Near-infrared Spectroscopy: Time-Derivative of Total Hemoglobin Concentration Change}

Among the parameters of NIRS, the peak time of maximum slope variation could be used to differentiate both the $\mathrm{OH}$ $\mathrm{Sx}$ and $\mathrm{OH}-\mathrm{BP}$ groups from the matched controls (Table 3, Figure 3). The average peak time of maximum slope variation was significantly longer in the $\mathrm{OH}-\mathrm{Sx}(18.5 \pm 2.9$ vs $17.3 \pm 2.1, p=0.015)$ and $\mathrm{OH}-\mathrm{BP}(19.4 \pm 3.1$ vs $17.2 \pm$ $2.0, p=0.022)$ groups than in the matched control groups. The $\mathrm{OH}-\mathrm{S} x$ group had delayed peak time of maximum slope variation in both the right and left hemispheres compared to the control group $(18.5 \pm 3.0$ vs $17.3 \pm 2.2, p=$ 0.029 and $18.5 \pm 3.0$ vs $17.4 \pm 2.2, p=0.022$, for the right and left peak time of maximum slope variations, respectively). Similarly, the peak time of maximum slope variation in both hemispheres was significantly different between the $\mathrm{OH}-\mathrm{BP}$ and control groups $(19.5 \pm 3.0$ vs $17.1 \pm 2.1, p=0.016,19.3 \pm 3.2$ vs $17.2 \pm 2.1, p=0.035$, for the right and left peak time of maximum slope variation, respectively). In addition, in the OH-BP subgrouping, the average peak time of maximum slope variation was significantly longer only in participants with orthostatic symptoms compared to the control group (20.4 \pm 3.5 vs $17.2 \pm 2.0, p=0.021)$. However, the minimum and maximum slope variations and the peak time of minimum slope variation could not differentiate among the $\mathrm{OH}-\mathrm{Sx}, \mathrm{OH}-\mathrm{BP}$, and control groups. 


\section{Discussion}

In this study, we measured temporal changes in $\mathrm{HbT}$ in the prefrontal cortex using portable NIRS during the squat-tostand maneuver in individuals with $\mathrm{OH} / \mathrm{OI}$ symptoms. The peak time of maximum slope variation of $\mathrm{HbT}$ change indicating the recovery rate and speed of CBV during the recovery stage after BP drop caused by abrupt posture change was significantly longer in the cases with $\mathrm{OH} / \mathrm{OI}$ symptoms compared to controls. The results suggested that $\mathrm{OH} / \mathrm{OI}$ symptoms are associated with dynamic alteration in cerebral HbT. Further, portable NIRS could be easily used for its assessment. Therefore, non-invasive NIRS signals that react to the cerebral hemodynamic response can be used to explain the $\mathrm{OH} / \mathrm{Ol}$ symptoms.

We categorized the participants into three groups of different severities based on the $\mathrm{OH}$ questionnaires (i.e., OHSA and OHDAS) and orthostatic BP drop during the supine-to-stand maneuver. The participants in OH-Sx group had $\mathrm{OH} / \mathrm{OI}$ symptoms even when the orthostatic BP change was not significant. However, some participants in the OH-BP group (OH-BP w/o Sx) did not have $\mathrm{OH} / \mathrm{Ol}$ symptoms despite experiencing severe orthostatic BP drop. This result supports the fact that despite the apparent orthostatic BP drop, some patients had milder OI symptom severity and were unaware of the $\mathrm{OH}$ symptoms ${ }^{[18]}$. Regardless of the severity of postural $\mathrm{BP}$ drop, $\mathrm{OH} / \mathrm{OI}$ symptoms were associated with prolongation of the peak time of maximum slope variation, which can be quantified using NIRS.

An excessive fall of peripheral BP from the conventional oscillometric cuff measurement was not present during the supine-to-stand maneuver in the $\mathrm{OH}-\mathrm{Sx}$ group, which suggests that the participants in this group had the delayed adaptation of the brain baroreflex despite a relatively intact peripheral baroreflex. Moreover, conventional peripheral BP and HR measurements cannot represent instantaneous cardiovascular responses after standing because at least 30 seconds are required to obtain a single measurement. As a result, even if there was no peripheral BP drop or noticeable $\mathrm{HR}$ increase measured immediately after posture change, the fluctuation in CBF could be altered, thus inducing OI symptoms. Our findings suggest that the cerebral hemodynamic response can be readily assessed using the peak time of maximum slope variation of HbT change.

As the squat-to-stand maneuver induces a large amount of venous blood pooling in the lower limbs, the average maximum SBP drop change was greater than $15 \mathrm{mmHg}$ for both the control and OH-Sx groups, but the drop was smaller in the $\mathrm{OH}-\mathrm{Sx}$ group than in the control group. Meanwhile, the $\mathrm{OH}-\mathrm{Sx}$ group experienced significant HR increase subsequent to postural change, suggesting that the participants in the $\mathrm{OH}-\mathrm{Sx}$ group had mild autonomic dysfunction due to rapid compensation of the BP drop ${ }^{[19]}$.

In a previous study, the time difference in peak time of maximum slope variation was strongly coupled to dysfunction in CBF autoregulation ${ }^{[9]}$. As shown in Figure 3, the average peak time of maximum slope variation increased in both the $\mathrm{OH}-\mathrm{Sx}$ and $\mathrm{OH}-\mathrm{BP}$ groups, especially in the OH-BP w/ Sx group, compared to the control. The overshoot amount of the $\mathrm{HbT}$, representing the recovery in $\mathrm{CBV}$ after squatting, is inversely proportional to the severity of $\mathrm{OH}$ and $\mathrm{Ol}^{[9]}$. Although, non-invasive signals that react to CBF changes can also be used with transcranial Doppler ultrasonography (TCD), the waveform of the time-derivative of $\mathrm{HbT}$ change in Figure $3 \mathrm{~B}$ and the CBF velocity measured in the middle cerebral artery using TCD during thigh-cuff inflation ${ }^{[20]}$ showed strong similarity. In fact, the squat-to-stand maneuver causes similar physiological changes to thigh-cuff release, resulting in a step-decrease in $\mathrm{BP}^{[21]}$. Moreover, TCD requires specific training for the examination, and the quality of the data may be influenced by individual skills or intrasubject variability of the temporal bone window. TCD can measure CBF velocity in large arteries, but NIRS can assess regional microvascular cerebral oxygenation. A combination of different monitoring techniques may improve our understanding of cerebral hemodynamics ${ }^{[22]}$. 
This study has several limitations. First, it was performed with a small population in one institution. Moreover, multiple studies have reported that $\mathrm{OH}$ is associated with cardiovascular disease, neurologic disorders, and some drugs, but we did not perform other cardiovascular or neurologic tests. However, the participants in this study were apparently healthy without history of these diseases and case-control matching with age, sex, HT, and DM was performed to avoid confounding factors. In order to verify our results, further multicenter study with a large sample size including individuals with diverse disease profiles is warranted. Second, we did not use continuous BP and HR monitoring and did not directly compare CBF measurements. A portable NIRS system may provide an indirect index of changes in CBF, but it can translate changes in $\mathrm{CBV}$ to dynamic alteration of CBF using the time-derivative of $\mathrm{HbT}$ change response during posture change ${ }^{[10]}$. Future studies with continuous BP and direct CBF measurements using TCD may help us understand the related hemodynamics and $\mathrm{OH} / \mathrm{OI}$ symptoms. Third, the $\mathrm{OH}-\mathrm{BP}$ group was identified using a supine-tostand maneuver, and there could have been individuals with false-negative $\mathrm{OH}$, where a tilt-table test could have increased the number of patients with OH-BP.

In conclusion, it was shown that the peak time of maximum slope variation of $\mathrm{HbT}$ change indicating the recovery rate and speed of CBV using portable NIRS on the forehead during the squat-to-stand maneuver was prolonged in individuals with $\mathrm{OH}$ and $\mathrm{Ol}$ symptoms compared to healthy controls. Our findings might provide new insight into understanding $\mathrm{OH}$ and $\mathrm{Ol}$ symptoms. The results suggested that $\mathrm{OH}$ and $\mathrm{Ol}$ are associated with dynamic alteration in the cerebral HbT-response. Further, portable NIRS could be easily used for its assessment.

\section{Declarations}

Acknowledgements: This work was funded by the Bio \& Medical Technology Development Program of the National Research Foundation (NRF) funded by the Korean government (2013M3A9B2076528). The funders had no role in the study design, data collection and analysis, decision to publish or preparation of the manuscript.

Author contributions: J.M.K, K.I.P., S.Y.C., and H.M.B designed and conceptualized the study; J.M.K, K.I.P, S.Y.C., H.E.P., and H.L. acquired the data; J.M.K, K.I.P., and S.Y.C analyzed the data; H.E.P. and H.L. interpreted the data; J.M.K., K.I.P., and S.Y.C. drafted the manuscript for intellectual content. H.E.P., H.L., and H.M.B. revised the manuscript for intellectual content.

Competing interests: There are no conflicts of interest to declare.

Data availability: Individual de-identified participant data will be shared by a request from any qualified investigator.

\section{References}

1. Byun, J. I. et al. Efficacy of single or combined midodrine and pyridostigmine in orthostatic hypotension. Neurology 89, 1078-1086 (2017). 10.1212/WNL.0000000000004340, Pubmed:28794253.

2. Juraschek, S. P. et al. Orthostatic hypotension, dizziness, neurology outcomes, and death in older adults. Neurology 95, e1941-e1950 (2020). 10.1212/WNL.0000000000010456, Pubmed:32732296.

3. Rouch, L. et al. Systolic blood pressure postural changes variability is associated with greater dementia risk. Neurology 95, e1932-e1940 (2020). 10.1212/WNL.0000000000010420, Pubmed:32690802.

4. Kaufmann, $\mathrm{H}$. Consensus statement on the definition of orthostatic hypotension, pure autonomic failure and multiple system atrophy. Clin. Auton. Res. 6, 125-126 (1996). 10.1007/BF02291236, Pubmed:8726100. 
5. Sagristà-Sauleda, J., Romero, B., Permanyer-Miralda, G., Moya, A. \& Soler-Soler, J. Reproducibility of sequential head-up tilt testing in patients with recent syncope, normal ECG and no structural heart disease. Eur. Heart J. 23, 17061713 (2002). 10.1053/euhj.2002.3166, Pubmed:12398829.

6. Macedo, P. et al. Head Up Tilt Testing: an appraisal of its current role in the management of patients with syncope. J. Atr. Fibrillation 4, 333 (2011). 10.4022/jafib.333, Pubmed:28496692.

7. Novak, V., Novak, P., Spies, J. M. \& Low, P. A. Autoregulation of cerebral blood flow in orthostatic hypotension. Stroke 29, 104-111 (1998). 10.1161/01.str.29.1.104, Pubmed:9445337.

8. Cope, M. \& Delpy, D. T. System for long-term measurement of cerebral blood and tissue oxygenation on newborn infants by near infra-red transillumination. Med. Biol. Eng. Comput. 26, 289-294 (1988). 10.1007/BF02447083, Pubmed:2855531.

9. Kim, J. M. et al. Assessment of cerebral autoregulation using continuous-wave near-infrared spectroscopy during squat-stand maneuvers in subjects with symptoms of orthostatic intolerance. Sci Rep, 13257. Sci. Rep. 8, 13257 (2018). 10.1038/s41598-018-31685-y, Pubmed:30185974.

10. Kainerstorfer, J. M., Sassaroli, A., Tgavalekos, K. T. \& Fantini, S. Cerebral autoregulation in the microvasculature measured with near-infrared spectroscopy. J. Cereb. Blood Flow Metab. 35, 959-966 (2015). 10.1038/jcbfm.2015.5, Pubmed:25669906.

11. Rivera-Lara, L. et al. Validation of near-infrared spectroscopy for monitoring cerebral autoregulation in comatose patients. Neurocrit. Care 27, 362-369 (2017). 10.1007/s12028-017-0421-8, Pubmed:28664392.

12. Terborg, C., Bramer, S., Harscher, S., Simon, M. \& Witte, O. W. Bedside assessment of cerebral perfusion reductions in patients with acute ischaemic stroke by near-infrared spectroscopy and indocyanine green. J. Neurol. Neurosurg. Psychiatry 75, 38-42 (2004). Pubmed:14707304.

13. Mol, A. et al. Cerebral autoregulation assessed by near-infrared spectroscopy: validation using transcranial Doppler in patients with controlled hypertension, cognitive impairment and controls. Eur. J. Appl. Physiol. 121, 2165-2176 (2021). 10.1007/s00421-021-04681-w, Pubmed:33860383.

14. Mol, A. et al. Sensitivity and reliability of cerebral oxygenation responses to postural changes measured with nearinfrared spectroscopy. Eur. J. Appl. Physiol. 119, 1117-1125 (2019). 10.1007/s00421-019-04101-0, Pubmed:30771059.

15. Kaufmann, H., Malamut, R., Norcliffe-Kaufmann, L., Rosa, K. \& Freeman, R. The Orthostatic Hypotension Questionnaire (OHQ): validation of a novel symptom assessment scale. Clin. Auton. Res. 22, 79-90 (2012). 10.1007/s10286-011-0146-2, Pubmed:22045363.

16. Takahashi, K. et al. A modeling of cerebral blood flow changes due to head motion for fNIRS. Int. J. Optomechatronics 7, 83-95 (2013). 10.1080/15599612.2013.777493.

17. Delpy, D. T. et al. Estimation of optical pathlength through tissue from direct time of flight measurement. Phys. Med. Biol. 33, 1433-1442 (1988). 10.1088/0031-9155/33/12/008, Pubmed:3237772.

18. Freeman, R. et al. Symptom recognition is impaired in patients with orthostatic hypotension. Hypertension 75 , 1325-1332 (2020). 10.1161/HYPERTENSIONAHA.119.13619, Pubmed:32223377. 
19. Freeman, R. et al. Consensus statement on the definition of orthostatic hypotension, neurally mediated syncope and the postural tachycardia syndrome. Clin. Auton. Res. 21, 69-72 (2011). 10.1007/s10286-011-0119-5, Pubmed:21431947.

20. Sorond, F. A., Serrador, J. M., Jones, R. N., Shaffer, M. L. \& Lipsitz, L. A. The sit-to-stand technique for the measurement of dynamic cerebral autoregulation. Ultrasound Med. Biol. 35, 21-29

(2009). 10.1016/j.ultrasmedbio.2008.08.001, Pubmed:18834658.

21. Tiecks, F. P., Lam, A. M., Aaslid, R. \& Newell, D. W. Comparison of static and dynamic cerebral autoregulation measurements. Stroke 26, 1014-1019 (1995). 10.1161/01.str.26.6.1014, Pubmed:7762016.

22. Klein, S. P., Depreitere, B. \& Meyfroidt, G. How I monitor cerebral autoregulation. Crit. Care 23, 160 (2019). 10.1186/s13054-019-2454-1, Pubmed:31064383.

\section{Tables}

Table 1 Clinical Characteristics. Values are presented as mean \pm standard deviation, number of patients $(\%)$. ${ }^{\star} \mathrm{P}<0.05$ compared with $\mathrm{OH}-\mathrm{Sx}$ matched controls, $\mathrm{\dagger P}<0.05$ compared with $\mathrm{OH}-\mathrm{BP}$ matched controls, $¥ \mathrm{P}<0.05$ compared between $\mathrm{OH}-\mathrm{BP}$ w Sx and OH-BP w/o Sx. OH-Sx, symptom alone group; OH-BP, classic orthostatic hypotension group, w/o Sx, without orthostatic hypotension symptom; w/ Sx, with orthostatic hypotension symptom; HTN, hypertension; DM, diabetes mellitus; BMI, body mass index; SBP, systolic blood pressure; DBP, Diastolic blood pressure; and HR, Heart rate; bpm, beat per minute. 


\begin{tabular}{|c|c|c|c|c|c|c|c|c|c|c|}
\hline Variables & $\begin{array}{l}\text { OH-Sx } \\
(n=69)\end{array}$ & $\begin{array}{l}\text { OH-Sx } \\
\text { matched } \\
\text { controls } \\
(n=69)\end{array}$ & $\underline{P}$ & $\begin{array}{l}\text { OH-BP } \\
(n=16)\end{array}$ & $\begin{array}{l}\text { OH-BP } \\
\text { matched } \\
\text { controls } \\
(n=16)\end{array}$ & $P$ & $\begin{array}{l}\mathrm{OH}- \\
\text { BP } \\
w / S x \\
(n=8)\end{array}$ & $\begin{array}{l}\mathrm{OH}- \\
\mathrm{BP} \\
\mathrm{w} / \mathrm{O} \\
\mathrm{Sx} \\
(n=8)\end{array}$ & $\begin{array}{l}\text { OH-BP } \\
\text { matched } \\
\text { controls } \\
(n=16)\end{array}$ & $\begin{array}{l}\text { Overall } \\
P\end{array}$ \\
\hline $\begin{array}{l}\text { Age, } \\
\text { (years) }\end{array}$ & $\begin{array}{l}44.2 \\
\pm 16.8\end{array}$ & $\begin{array}{l}44.8 \\
\pm 16.6\end{array}$ & 0.780 & $\begin{array}{l}54 \\
\pm 21\end{array}$ & $\begin{array}{l}54.1 \\
\pm 20.4\end{array}$ & 0.838 & $\begin{array}{l}47.4 \\
\pm 24.9\end{array}$ & $\begin{array}{l}60.6 \\
\pm 15.1\end{array}$ & $\begin{array}{l}54.1 \\
\pm 20.4\end{array}$ & 0.599 \\
\hline Men, (\%) & $\begin{array}{l}25 \\
(36.2)\end{array}$ & $25(36.2)$ & 1.000 & $\begin{array}{l}7 \\
(43.8)\end{array}$ & $7(43.8)$ & 1.000 & $4(50)$ & $\begin{array}{l}3 \\
(37.5)\end{array}$ & $7(43.8)$ & 0.881 \\
\hline HTN, (\%) & $5(7.2)$ & $5(7.2)$ & 1.000 & $\begin{array}{l}2 \\
(12.5)\end{array}$ & $2(12.5)$ & 1.000 & $\begin{array}{l}1 \\
(12.5)\end{array}$ & $\begin{array}{l}1 \\
(12.5)\end{array}$ & $2(12.5)$ & 1.000 \\
\hline DM, (\%) & $2(2.9)$ & $2(2.9)$ & 1.000 & $\begin{array}{l}1 \\
(6.25)\end{array}$ & $1(6.25)$ & 1.000 & $0(0)$ & $\begin{array}{l}1 \\
(12.5)\end{array}$ & $1(6.25)$ & 0.587 \\
\hline $\begin{array}{l}\text { BMI, } \\
\mathrm{kg} / \mathrm{m}^{2}\end{array}$ & $\begin{array}{l}21.7 \\
\pm 3.1\end{array}$ & $21.6 \pm 2.9$ & 0.833 & $\begin{array}{l}21.8 \\
\pm 2.1\end{array}$ & $22 \pm 2.7$ & 0.755 & $\begin{array}{l}22.3 \\
\pm 2.5\end{array}$ & $\begin{array}{l}21.3 \\
\pm 1.6\end{array}$ & $22 \pm 2.7$ & 0.665 \\
\hline OHSA & $\begin{array}{l}3.9 \\
\pm 2 *\end{array}$ & $0.5 \pm 0.6$ & 0.000 & $\begin{array}{l}2.1 \\
\pm 2^{\dagger}\end{array}$ & $0.5 \pm 0.7$ & 0.001 & $\begin{array}{l}3.3 \\
\pm 2.3^{\dagger}\end{array}$ & $\begin{array}{l}1 \\
\pm 0.6\end{array}$ & $0.5 \pm 0.7$ & 0.001 \\
\hline OHDAS & $\begin{array}{l}2 \\
\pm 2.1^{*}\end{array}$ & $0.2 \pm 0.4$ & 0.000 & $\begin{array}{l}1.6 \\
\pm 1.9^{\dagger}\end{array}$ & $0.2 \pm 0.4$ & 0.011 & $\begin{array}{l}2.9 \\
\pm 2^{\dagger \neq}\end{array}$ & $\begin{array}{l}0.3 \\
\pm 0.5\end{array}$ & $0.2 \pm 0.4$ & 0.000 \\
\hline $\begin{array}{l}\text { Baseline } \\
\text { SBP, } \\
\text { mmHg }\end{array}$ & $\begin{array}{r}114.5 \\
\pm 11.9\end{array}$ & $\begin{array}{r}118.1 \\
\pm 13.2\end{array}$ & 0.087 & $\begin{array}{r}118.5 \\
\pm 11.7\end{array}$ & $\begin{array}{l}124 \\
\pm 15.4\end{array}$ & 0.261 & $\begin{array}{l}119.1 \\
\pm 12\end{array}$ & $\begin{array}{r}117.9 \\
\pm 12.1\end{array}$ & $\begin{array}{l}124 \\
\pm 15.4\end{array}$ & 0.529 \\
\hline $\begin{array}{l}\text { Baseline } \\
\text { DBP, } \\
\text { mmHg }\end{array}$ & $\begin{array}{l}75.2 \\
\pm 8.4\end{array}$ & $77.1 \pm 9.6$ & 0.218 & $\begin{array}{l}76.3 \\
\pm 8.5\end{array}$ & $\begin{array}{l}76.9 \\
\pm 10.5\end{array}$ & 0.861 & $\begin{array}{r}75.9 \\
\pm 9.9\end{array}$ & $\begin{array}{l}76.8 \\
\pm 7.5\end{array}$ & $\begin{array}{l}76.9 \\
\pm 10.5\end{array}$ & 0.971 \\
\hline $\begin{array}{l}\text { Baseline } \\
\text { HR, bpm }\end{array}$ & $\begin{array}{l}74.9 \\
\pm 11.1\end{array}$ & $\begin{array}{l}73.4 \\
\pm 10.4\end{array}$ & 0.387 & $\begin{array}{l}72.3 \\
\pm 11.4\end{array}$ & $\begin{array}{l}71.6 \\
\pm 12.5\end{array}$ & 0.564 & $\begin{array}{l}73.8 \\
\pm 11.4\end{array}$ & $\begin{array}{l}70.9 \\
\pm 11.8\end{array}$ & $\begin{array}{l}71.6 \\
\pm 12.5\end{array}$ & 0.837 \\
\hline
\end{tabular}

Table 2 Blood pressure and heart rate results during supine- and squat- to stand maneuvers. Values are presented as mean \pm standard deviation. ${ }^{*} \mathrm{P}<0.05$ compared with $\mathrm{OH}-\mathrm{Sx}$ matched controls, $+\mathrm{P}<0.05$ compared with $\mathrm{OH}-\mathrm{BP}$ matched controls. OH-Sx indicates symptom alone group; OH-BP, classic orthostatic hypotension group, w/o Sx, without orthostatic hypotension symptom; w/ Sx, with orthostatic hypotension symptom; SBP, systolic blood pressure; DBP, Diastolic blood pressure; and HR, Heart rate; bpm, beat per minute. 


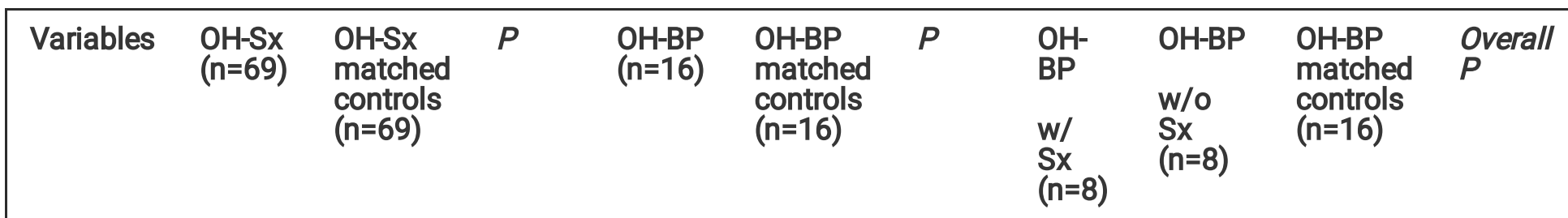

\section{Supine to stand}

Maximum change during 3 minutes

$\begin{array}{lllllllllll}\text { SBP, } & -1.7 & -3.1 \pm 7.8 & 0.286 & -27.8 & -3.1 \pm 7.4 & 0.000 & -24.5 & -31.1 & -3.1 \pm 7.4 & 0.000 \\ \text { mmHg } & \pm 7.0 & & & \pm 9.0 \dagger & & & \pm 4.7 \dagger & \pm 11.2 \dagger & & \\ \text { DBP, } & 5.0 & 4.8 \pm 5.6 & 0.823 & -4.4 & 3.5 \pm 5.3 & 0.008 & 0.3 & -9.1 & 3.5 \pm 5.3 & 0.001 \\ \text { mmHg } & \pm 5.0 & & & \pm 9.6 \dagger & & & \pm 6.5 & \pm 10.3 \dagger & & \\ & & & & & & & & & \\ \mathrm{HR}, \mathrm{bpm} & 14.7 & 15.4 & 0.370 & 16.3 & 11.8 & 0.254 & 20.8 & 11.9 & 11.8 & 0.040 \\ & \pm 8.5 & \pm 8.0 & & \pm 17.1 & \pm 5.1 & & \pm 12.7 & \pm 7.6 & \pm 5.1 & \end{array}$

Maximum change during 10 minutes

\begin{tabular}{|c|c|c|c|c|c|c|c|c|c|c|}
\hline $\begin{array}{l}\text { SBP, } \\
\mathrm{mm} H \mathrm{Hg}\end{array}$ & $\begin{array}{l}-3.3 \\
\pm 7.1\end{array}$ & $-4.5 \pm 6.9$ & 0.322 & $\begin{array}{l}-29.2 \\
\pm 10.0+\end{array}$ & $-4.1 \pm 7.5$ & 0.000 & $\begin{array}{l}-26.5 \\
\pm 6.8+\end{array}$ & $\begin{array}{l}-31.9 \\
\pm 12.2 \dagger\end{array}$ & $-4.1 \pm 7.5$ & 0.000 \\
\hline $\begin{array}{l}\text { DBP, } \\
\text { mmHg }\end{array}$ & $\begin{array}{l}3.7 \\
\pm 5.5\end{array}$ & $4.1 \pm 5.4$ & 0.710 & $\begin{array}{l}-5.8 \\
\pm 8.9+\end{array}$ & $3.1 \pm 5.1$ & 0.002 & $\begin{array}{l}-2.4 \\
\pm 6.1\end{array}$ & $\begin{array}{l}-9.1 \\
\pm 10.3+\end{array}$ & $3.1 \pm 5.1$ & 0.001 \\
\hline $\mathrm{HR}$, bpm & $\begin{array}{l}16.1 \\
\pm 8.7\end{array}$ & $17 \pm 8.5$ & 0.236 & $\begin{array}{l}17.8 \\
\pm 12.0\end{array}$ & $\begin{array}{l}13.0 \\
\pm 5.2\end{array}$ & 0.402 & $\begin{array}{l}22.4 \\
\pm 14.0\end{array}$ & $\begin{array}{l}13.3 \\
\pm 8.2\end{array}$ & $\begin{array}{l}13.0 \\
\pm 5.2\end{array}$ & 0.049 \\
\hline
\end{tabular}

\section{Squat to stand}

Maximum change during 3 minutes

$\begin{array}{lllllllllll}\text { SBP, } & -14.3 & -18.9 & 0.007 & -39.6 & -18.2 & 0.002 & -36.1 & -43.1 & -18.2 & 0.006 \\ \text { mmHg } & \pm 13.0^{\star} & \pm 12.3 & & \pm 22.3+ & \pm 11.8 & & \pm 28.5 & \pm 14.9 \dagger & \pm 11.8 & \\ \text { DBP, } & -6.6 & -8.3 \pm 6.9 & 0.132 & -15.9 & -7.9 \pm 6.1 & 0.050 & -13.0 & -18.8 & -7.9 \pm 6.1 & 0.032 \\ \text { mmHg } & \pm 6.6 & & & \pm 14.1 & & & \pm 18.1 & \pm 8.8 \dagger & & \\ & & & & & & & & & \\ \text { HR, bpm } & 15.4 & 10.9 & 0.020 & 13.9 & 9.6 \pm 6.6 & 0.445 & 16.1 & 11.6 & 9.6 \pm 6.6 & 0.687 \\ & \pm 10.4^{\star} & \pm 9.7 & & \pm 12.8 & & & \pm 15.8 & \pm 9.5 & & \end{array}$

Maximum change during 10 minutes

$\begin{array}{lllllllllll}\text { SBP, } & -16.8 & -21.5 & 0.003 & -41.2 & -21.3 & 0.003 & -37.5 & -44.9 & -21.3 & 0.008 \\ \text { mmHg } & \pm 12.3^{*} & \pm 12.0 & & \pm 21.9+ & \pm 10.0 & & \pm 28.8 & \pm 13.2 \dagger & \pm 10.0 & \\ \text { DBP, } & -7.4 & -9.2 \pm 6.8 & 0.090 & -16.4 & -8.5 \pm 5.8 & 0.050 & -13.3 & -19.6 & -8.5 \pm 5.8 & 0.036 \\ \text { mmHg } & \pm 6.1 & & & \pm 14.1 & & & \pm 18.0 & \pm 8.9 \dagger & & \\ \text { HR, bpm } & 16.8 & 12.3 & 0.015 & 14.5 & 9.9 \pm 6.0 & 0.323 & 17.0 & 12.0 & 9.9 \pm 6.0 & 0.522 \\ & \pm 10.4^{\star} & \pm 9.8 & & \pm 12.6 & & & \pm 15.5 & \pm 9.1 & & \end{array}$

Table 3. Parameters of near-infrared spectroscopy: the slope variations of the total hemoglobin concentration change and the corresponding peak times of the time-derivative of total hemoglobin concentration in each hemisphere. Values are presented as mean \pm standard deviation. ${ }^{*} \mathrm{P}<0.05$ compared with $\mathrm{OH}-\mathrm{Sx}$ matched controls, $\mathrm{tP}<0.05$ compared with $\mathrm{OH}-\mathrm{BP}$ matched controls. OH-Sx indicates symptom alone group; $\mathrm{OH}-\mathrm{BP}$, classic orthostatic hypotension group, w/o $\mathrm{Sx}$, without orthostatic hypotension symptom; w/ Sx, with orthostatic hypotension symptom. 


\begin{tabular}{|c|c|c|c|c|c|c|c|c|c|c|}
\hline Variables & $\begin{array}{c}\text { OH-Sx } \\
(n=69)\end{array}$ & $\begin{array}{l}\text { OH-Sx } \\
\text { matched } \\
\text { controls } \\
(n=69)\end{array}$ & $P$ & $\begin{array}{l}\text { OH-BP } \\
(n=16)\end{array}$ & $\begin{array}{l}\text { OH-BP } \\
\text { matched } \\
\text { controls } \\
(n=16)\end{array}$ & $P$ & $\begin{array}{l}\mathrm{OH}- \\
\mathrm{BP} \\
\mathrm{w} / \\
\mathrm{Sx} \\
(n=8)\end{array}$ & $\begin{array}{l}\mathrm{OH}- \\
\mathrm{BP} \\
\mathrm{w} / 0 \\
\mathrm{Sx} \\
(n=8)\end{array}$ & $\begin{array}{l}\text { OH-BP } \\
\text { matched } \\
\text { controls } \\
(n=16)\end{array}$ & $\begin{array}{l}\text { Overall } \\
P\end{array}$ \\
\hline \multicolumn{11}{|c|}{ Minimum slope variation } \\
\hline $\begin{array}{l}\text { Left, } \\
\mathrm{mM} / \mathrm{s}\end{array}$ & $\begin{array}{l}-6.1 \\
\pm 3.3\end{array}$ & $-6.0 \pm 2.8$ & 0.983 & $\begin{array}{l}-7.7 \\
\pm 5.2\end{array}$ & $-6.2 \pm 3.0$ & 0.184 & $\begin{array}{l}-8.7 \\
\pm 7.3\end{array}$ & $\begin{array}{l}-6.7 \\
\pm 1.5\end{array}$ & $-6.2 \pm 3.0$ & 0.355 \\
\hline $\begin{array}{l}\text { Right, } \\
\mathrm{mM} / \mathrm{s}\end{array}$ & $\begin{array}{l}-6.6 \\
\pm 4.2\end{array}$ & $-6.8 \pm 3.4$ & 0.821 & $\begin{array}{l}-7.3 \\
\pm 4.9\end{array}$ & $-6.9 \pm 3.1$ & 1.000 & $\begin{array}{l}-7.9 \\
\pm 6.7\end{array}$ & $\begin{array}{l}-6.7 \\
\pm 2.5\end{array}$ & $-6.9 \pm 3.1$ & 0.996 \\
\hline $\begin{array}{l}\text { Average, } \\
\mathrm{mM} / \mathrm{s}\end{array}$ & $\begin{array}{l}-6.4 \\
\pm 3.5\end{array}$ & $-6.4 \pm 2.9$ & 0.963 & $\begin{array}{l}-7.5 \\
\pm 4.9\end{array}$ & $-6.6 \pm 2.8$ & 0.564 & $\begin{array}{l}-8.3 \\
\pm 6.9\end{array}$ & $\begin{array}{l}-6.7 \\
\pm 1.9\end{array}$ & $-6.6 \pm 2.8$ & 0.823 \\
\hline \multicolumn{11}{|c|}{ The peak time of minimum slope variation } \\
\hline Left, sec & $\begin{array}{l}6.5 \\
\pm 1.9\end{array}$ & $6.5 \pm 1.8$ & 0.915 & $\begin{array}{l}6.7 \\
\pm 2.1\end{array}$ & $6.4 \pm 2.3$ & 0.689 & $\begin{array}{l}6.6 \\
\pm 2.5\end{array}$ & $\begin{array}{l}6.8 \\
\pm 1.7\end{array}$ & $6.4 \pm 2.3$ & 0.916 \\
\hline $\begin{array}{l}\text { Right, } \\
\text { sec }\end{array}$ & $\begin{array}{l}6.4 \\
\pm 2.0\end{array}$ & $6.3 \pm 1.5$ & 0.676 & $\begin{array}{l}6.8 \\
\pm 2.0\end{array}$ & $6.1 \pm 1.6$ & 0.307 & $\begin{array}{l}6.9 \\
\pm 2.2\end{array}$ & $\begin{array}{l}6.7 \\
\pm 1.8\end{array}$ & $6.1 \pm 1.6$ & 0.584 \\
\hline $\begin{array}{l}\text { Average, } \\
\text { sec }\end{array}$ & $\begin{array}{l}6.5 \\
\pm 1.7\end{array}$ & $6.4 \pm 1.3$ & 0.763 & $\begin{array}{l}6.7 \\
\pm 2.0\end{array}$ & $6.2 \pm 1.7$ & 0.466 & $\begin{array}{l}6.7 \\
\pm 2.4\end{array}$ & $\begin{array}{l}6.7 \\
\pm 1.8\end{array}$ & $6.2 \pm 1.7$ & 0.770 \\
\hline \multicolumn{11}{|c|}{ Maximum slope variation } \\
\hline $\begin{array}{l}\text { Left, } \\
\mathrm{mM} / \mathrm{s}\end{array}$ & $\begin{array}{l}5.1 \\
\pm 3.1\end{array}$ & $5.3 \pm 3.6$ & 0.713 & $\begin{array}{l}5.2 \\
\pm 3.7\end{array}$ & $5.4 \pm 3.2$ & 0.669 & $\begin{array}{l}5.6 \\
\pm 4.8\end{array}$ & $\begin{array}{l}4.7 \\
\pm 2.4\end{array}$ & $5.4 \pm 3.2$ & 0.891 \\
\hline $\begin{array}{l}\text { Right, } \\
\mathrm{mM} / \mathrm{s}\end{array}$ & $\begin{array}{l}5.5 \\
\pm 4.3\end{array}$ & $5.8 \pm 3.7$ & 0.686 & $\begin{array}{l}5.3 \\
\pm 3.5\end{array}$ & $5.7 \pm 3.5$ & 0.696 & $\begin{array}{l}5.9 \\
\pm 4.5\end{array}$ & $\begin{array}{l}4.7 \\
\pm 2.4\end{array}$ & $5.7 \pm 3.5$ & 0.872 \\
\hline $\begin{array}{l}\text { Average, } \\
\mathrm{mM} / \mathrm{s}\end{array}$ & $\begin{array}{l}5.3 \\
\pm 3.5\end{array}$ & $5.5 \pm 3.6$ & 0.686 & $\begin{array}{l}5.2 \\
\pm 3.5\end{array}$ & $5.6 \pm 3.3$ & 0.752 & $\begin{array}{l}5.7 \\
\pm 4.5\end{array}$ & $\begin{array}{l}4.7 \\
\pm 2.3\end{array}$ & $5.6 \pm 3.3$ & 0.941 \\
\hline \multicolumn{11}{|c|}{ The peak time of maximum slope variation } \\
\hline Left, sec & $\begin{array}{l}18.5 \\
\pm 3.0 *\end{array}$ & $17.4 \pm 2.2$ & 0.022 & $\begin{array}{l}19.3 \\
\pm 3.2^{\dagger}\end{array}$ & $17.2 \pm 2.1$ & 0.035 & $\begin{array}{l}20.6 \\
\pm 3.5^{\dagger}\end{array}$ & $\begin{array}{l}18.0 \\
\pm 2.6\end{array}$ & $\begin{array}{l}17.2 \\
\pm 2.1\end{array}$ & 0.018 \\
\hline $\begin{array}{l}\text { Right, } \\
\text { sec }\end{array}$ & $\begin{array}{l}18.5 \\
\pm 3.0 *\end{array}$ & $17.3 \pm 2.2$ & 0.029 & $\begin{array}{l}19.5 \\
\pm 3^{\dagger}\end{array}$ & $17.1 \pm 2.1$ & 0.016 & $\begin{array}{l}20.2 \\
\pm 3.5^{\dagger}\end{array}$ & $\begin{array}{l}18.7 \\
\pm 2.3\end{array}$ & $\begin{array}{l}17.1 \\
\pm 2.1\end{array}$ & 0.027 \\
\hline $\begin{array}{l}\text { Average, } \\
\text { sec }\end{array}$ & $\begin{array}{l}18.5 \\
\pm 2.9 *\end{array}$ & $17.3 \pm 2.1$ & 0.015 & $\begin{array}{l}19.4 \\
\pm 3.1^{\dagger}\end{array}$ & $17.2 \pm 2$ & 0.022 & $\begin{array}{l}20.4 \\
\pm 3.5^{\dagger}\end{array}$ & $\begin{array}{l}18.4 \\
\pm 2.4\end{array}$ & $17.2 \pm 2$ & 0.021 \\
\hline
\end{tabular}

Figures 


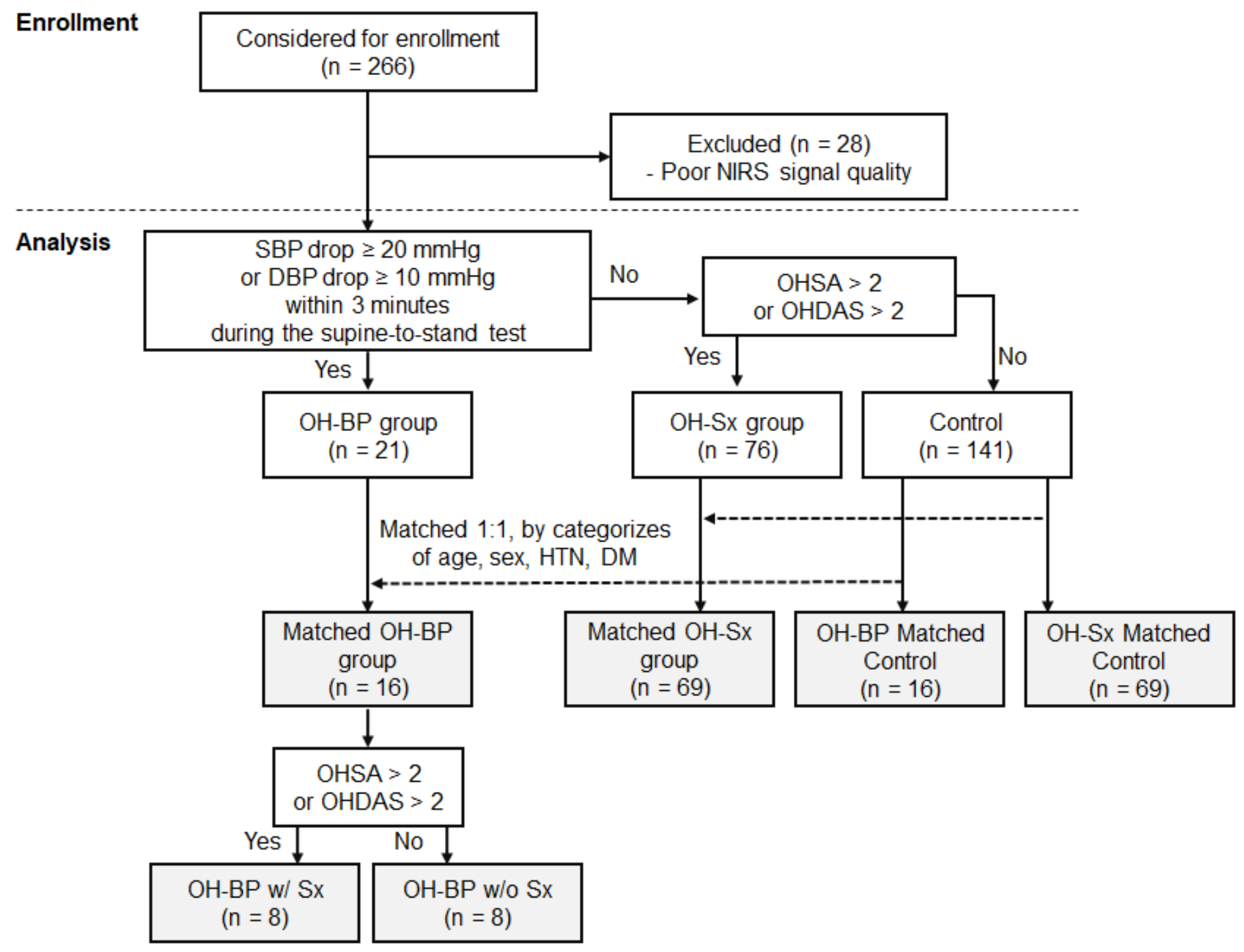

\section{Figure 1}

Flow chart of study design and group definitions

SBP, systolic blood pressure; DBP, diastolic blood pressure; NIRS, near infrared spectroscopy; OHDAS, Orthostatic Hypotension Daily Activity Scale; OHSA, Orthostatic Hypotension Symptom Assessment; OH-Sx, symptom alone group; w/o Sx, without orthostatic hypotension symptom; w/ Sx, with orthostatic hypotension symptom. 

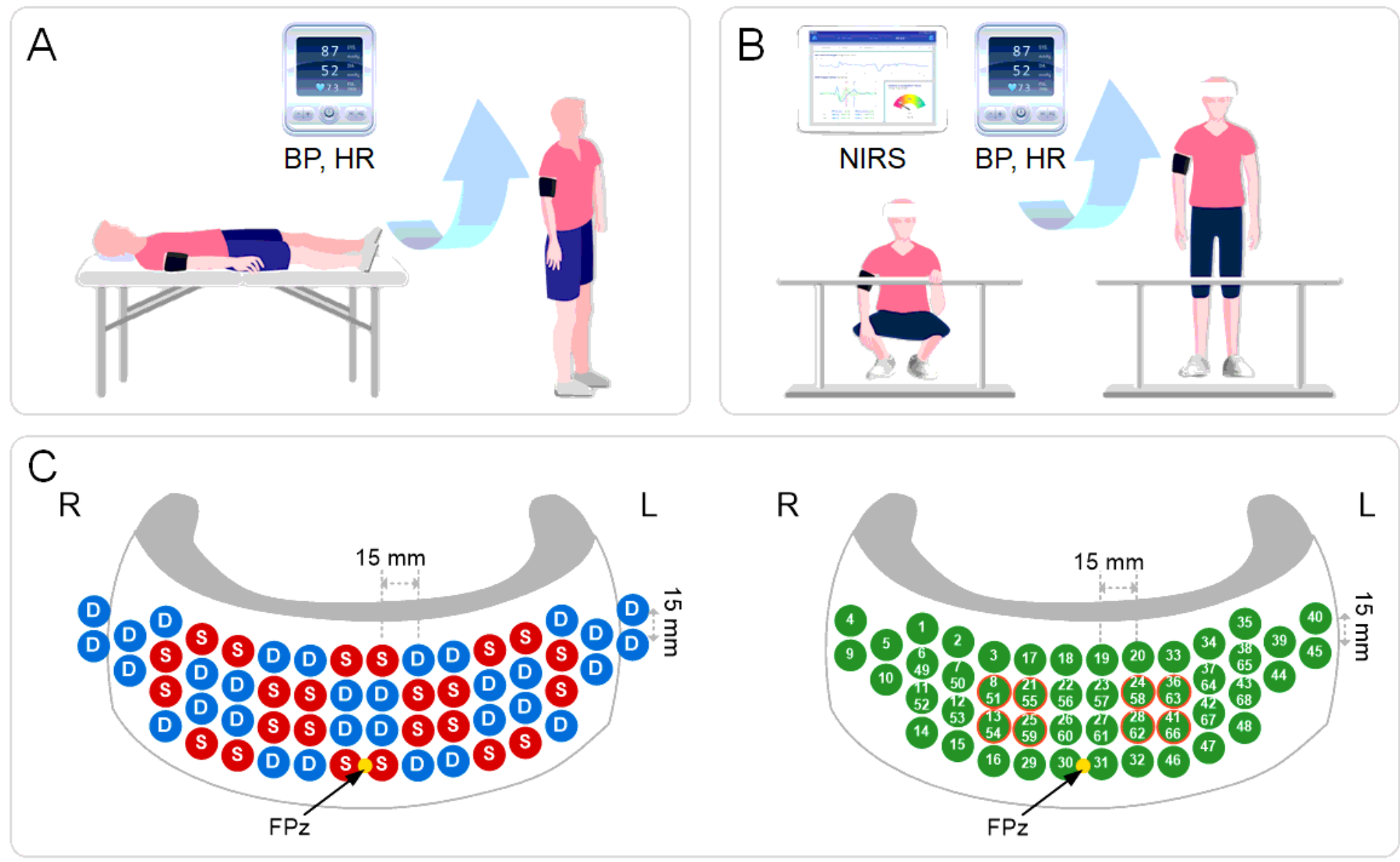

Figure 2

Measurement setup and optode and channel position of the NIRS system

(A) Measurement setup for supine-to-stand maneuver, (B) Measurement setup for squat-to-stand maneuver, and (C) Optode and channel position.

BP, blood pressure; NIRS, near-infrared spectroscopy; Fpz, frontopolar zero; HR, heart rate; L, left; R, right. 

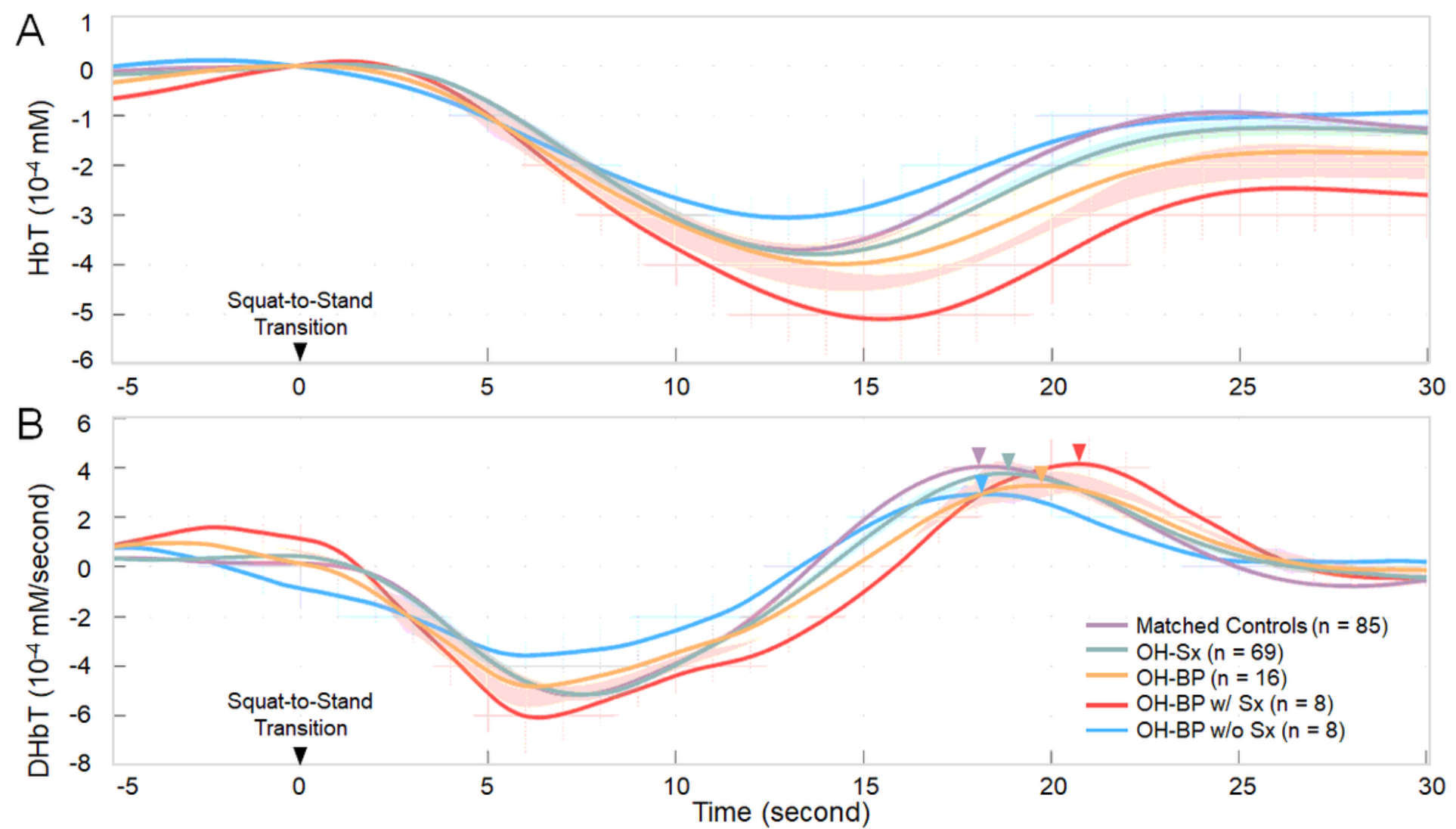

Figure 3

Cerebral hemodynamic response during the squat-to-stand maneuver

Each graph represents the average result (solid line) and standard error of the mean (shade) of each group. Colored arrows represent the point of the peak time of maximum slope variation from total hemoglobin concentration change of each group. (A) total hemoglobin concentration response and (B) time-derivative of total hemoglobin concentration response.

$\mathrm{OH}$, orthostatic hypotension; $\mathrm{OH}-\mathrm{Sx}$, symptom alone group; OH-BP, classic OH group; w/o Sx, without orthostatic hypotension symptom; w/ Sx, with orthostatic hypotension symptom; HbT, total hemoglobin concentration; DHbT, time-derivative of total hemoglobin concentration change

\section{Supplementary Files}

This is a list of supplementary files associated with this preprint. Click to download.

- ChoiSupplementaryMaterial.docx 